\title{
A survey of strong high-frequency sea level oscillations along the US East Coast between 2006 and 2011
}

\author{
S. Pasquet, I. Vilibić, and J. Šepić \\ Institute of Oceanography and Fisheries, Split, Croatia \\ Correspondence to: S. Pasquet (pasquet@izor.hr) \\ Received: 9 July 2012 - Published in Nat. Hazards Earth Syst. Sci. Discuss.: - \\ Revised: 27 November 2012 - Accepted: 2 January 2013 - Published: 20 February 2013
}

\begin{abstract}
A systematic survey of high-frequency sea level oscillations $(<6 \mathrm{~h})$ measured between 2006 and 2011 along the US East Coast is performed. Raw 1-min resolution sea level data is used. After performing a data quality check, the nine most intense events, with maximum recorded wave heights ranging from 40 to $100 \mathrm{~cm}$, are identified. Focusing on three of these events enables us to recognize two different generation mechanisms: (i) topographically-trapped edge waves which are found to be a significant contributor to the strongest observed oscillations, and (ii) standing waves, which occur over enclosed shallow waters and may result in significant wave heights of up to $100 \mathrm{~cm}$. A reproduction of the observed oscillations is a part of a future work, which will include an assessment of a generating force in the atmosphere, allowing for a better prevention of potential flooding along the US East Coast.
\end{abstract}

\section{Introduction}

High-frequency sea level oscillations with periods ranging from several minutes to a day in coastal regions result from a variety of processes: tides, direct forcing from the atmosphere, and different kinds of propagating and standing ocean waves, all of which can be amplified over shelves, in bays, harbours and over other topographical features (LeBlond and Mysak, 1977). Some sea level components (e.g. tides) are forecasted precisely, some are forecasted satisfactorily (e.g. storm surges), but others occur suddenly (e.g. tsunamis) and can lead to severe coastal floods where coastal infrastructure is not adopted properly. Tsunamis are the best example (Bernard et al., 2006); however, atmospherically generated ocean gravity waves and coastal edge waves can also cause severe flooding, especially in harbours characterised by a large amplification factor (Rabinovich, 2009).

Many barotropic ocean processes can be significantly amplified over a wide shelf; as energy coming from the open ocean or atmosphere can be efficiently trapped there (Vennell, 2010). For example, hurricane- or cyclonegenerated coastally trapped waves occurring over a sloping shelf often have a meter scale (Yankovsky, 2008; Eliot and Pattiaratchi, 2010). Edge waves, occurring over super-inertial timescales, are amplified towards the coastline due to refraction and reflection of long ocean waves over the sloping topography (Huthnance, 1975; Yankovsky, 2008). Meteotsunami, long ocean waves resonantly generated over the shelf by a travelling atmospheric disturbance (Monserrat et al., 2006), are as well amplified over the shelf. At the coastline, oscillations can further amplify within harbours and bays through harbour resonant processes, which can result in a several-meter-high oscillations over a several minute timescale (Rabinovich, 2009).

A wide shelf, with a width varying from $50 \mathrm{~km}$ (south Florida and North Carolina) to $500 \mathrm{~km}$ (Gulf of Maine), encompasses most of the US East Coast. A number of studies document this shelf as a place where long ocean waves are atmospherically generated (Yankovsky, 2008; Churchill et al., 1995). Both generation and propagation of edge waves along the US coastline have been documented several times during the last $60 \mathrm{yr}$ (Munk et al., 1956; Greenspan, 1956; Beardsley et al., 1977). Tropical cyclones moving northward are usually the principal generating source of these coastal waves (Yankovsky, 2008, 2009). An early study by Donn and McGuinness (1960) focused on the effect of 4-10 min air pressure oscillations on the sea level, 80 miles away from New York City. They found that the inverted barometer 
Table 1. List of the tide gauge stations along the US East Coast used for the analysis.

\begin{tabular}{llrrl}
\hline $\begin{array}{l}\text { Station } \\
\text { number }\end{array}$ & Name & Latitude & Longitude & $\begin{array}{l}\text { Time } \\
\text { sampling }\end{array}$ \\
\hline 8413320 & Bar Harbor & 44.3917 & $-68,205$ & $1 \mathrm{~min}$ \\
8418150 & Portland & 43.6567 & -70.2467 & $1 \mathrm{~min}$ \\
8419317 & Wells & 43.32 & -70.5633 & $1 \mathrm{~min}$ \\
8423898 & Fort Point & 43.0717 & -70.7117 & $6 \mathrm{~min}$ \\
8443970 & Boston & 42.355 & -71.0517 & $1 \mathrm{~min}$ \\
8448725 & Menemsha & 41.3544 & -70.7678 & $6 \mathrm{~min}$ \\
8449130 & Nantucket Island & 41.285 & -70.0967 & $1 \mathrm{~min}$ \\
8510560 & Montauk & 41.0483 & -71.96 & $1 \mathrm{~min}$ \\
8531680 & Sandy Hook & 40.4667 & -74.01 & $1 \mathrm{~min}$ \\
8534720 & Atlantic City & 39.355 & -74.4183 & $1 \mathrm{~min}$ \\
8536110 & Cape May & 38.9683 & -74.96 & $1 \mathrm{~min}$ \\
8557380 & Lewes & 38.7817 & -75.12 & $1 \mathrm{~min}$ \\
8570283 & Ocean City Inlet & 38.32833 & -75.091667 & $1 \mathrm{~min}$ \\
8638863 & Chesapeake Bay Bridge Tunnel & 36.966667 & -76.113333 & $1 \mathrm{~min}$ \\
8651370 & Duck & 36.183333 & -75.746667 & $1 \mathrm{~min}$ \\
8652587 & Oregon & 35.795 & -75.5483 & $1 \mathrm{~min}$ \\
8656483 & Beaufort & 34.72 & -76.67 & $1 \mathrm{~min}$ \\
8658163 & Wrightsville Beach & 34.2133 & -77.7867 & $1 \mathrm{~min}$ \\
8661070 & Springmaid Pier & 33.655 & -78.9183 & $1 \mathrm{~min}$ \\
8721604 & Trident Pier & 28.415 & -80.5933 & $1 \mathrm{~min}$ \\
\hline & & & & \\
\hline
\end{tabular}

response was dynamically multiplied by about 100 times. Several other papers deal with the resonant energy transfer over the shelf (Donn and Balachandran, 1960; Churchill et al., 1995; Paxton and Sobien, 1998). Tropical storm and associated long ocean waves have been found to excite onemeter-high sea level oscillations over the coasts of Newfoundland (Mercer et al., 2002; Mecking et al., 2009); both resonantly generated waves and waves reflected/refracted at the shelf edge are found to contribute to the observed coastal sea level oscillations.

The most intense sea level event along the US East Coast occurred at Daytona Beach, Florida, on 3 July 1992 (Sallanger et al., 1995; Churchill et al., 1995). Daytona Beach was hit by 3-m-high waves, hypothesized to be a result of alongshore propagating squall line, which resonantly generated long ocean waves through the Proudman resonance.

All of these events were a posteriori examined, while no systematic investigations on the East Coast high-frequency sea level oscillations were conducted. Our research aimed to systematically survey the strongest sea level oscillations over short timescales ( $6 \mathrm{~h}$ or less) observed along the US East Coast between 2006 and 2011, when sea level data at 1-min resolution were available along the whole coastline. The data and the methods will be presented in Sect. 2; Sect. 3 will focus on three selected events and display their different nature and underlying physical processes, ending with some discussion and conclusions outlined in Sect. 4.

\section{Data and methods}

Sea level data covering the period of 2006 to 2011 were taken from twenty tide gauge stations spread along the US East Coast from $28^{\circ} 30^{\prime} \mathrm{N}$ (Trident Pier) to $44^{\circ} 25^{\prime} \mathrm{N}$ (Bar Harbor). Sea level and meteorological data were downloaded from the NOAA CO-OPS website at http://opendap.co-ops.nos.noaa. gov/axis/webservices, while MERRA website (http://gmao. gsfc.nasa.gov/merra) was used for investigations of synoptic conditions. The 1-min raw data were used when available, in order to properly capture high-frequency events. Otherwise, 6-min preliminary data were used when 1-min resolution was not available. Table 1 contains basic information about the stations, while Fig. 1 illustrates their geographical positions.

Several quality check analyses indicated a number of problems with 1-min sea level raw data. The corrupted data are detected through a presence of isolated spikes, gaps in the time series and sometimes several hours of continuous aberrant values. Isolated spikes differing for more than $20 \mathrm{~cm}$ from neighbouring values were removed. Other bad data were removed manually after visual inspection. An example is shown in Fig. 2, where the presence of bad 1-min sea level data results in artificial peaks and oscillation throughout the time series, when detiding and digital filtering is applied. Several stations had abnormal fluctuations during the studied period, and these fluctuations were all removed manually before further processing.

T-tide software package (Pawlowitz et al., 2002) was used to subtract tides from the series. The subtraction has been done on the whole time series, i.e. over $5 \mathrm{yr}$ of data span, 


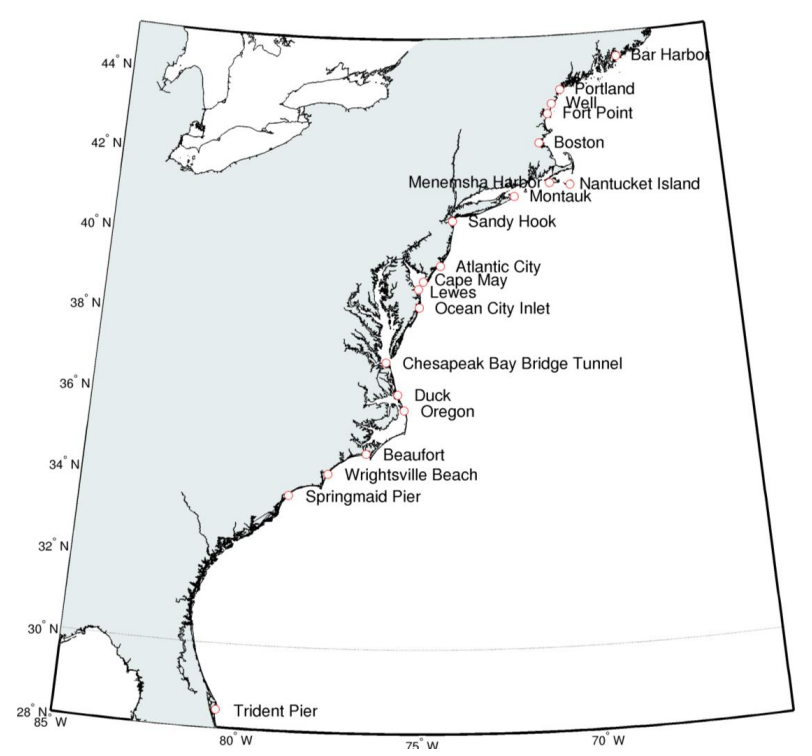

Fig. 1. Positions of the tide gauges along the US East Coast used in the analyses.

removing all significant tidal harmonics from $M_{\text {sf }}$ to $M=8$ from the series. Residuals were high-pass filtered with a 6-h Kaiser-Bessel digital filter, in order to document the strongest oscillations with periods shorter than $6 \mathrm{~h}$. Once detected, we also used a 12-h Kaiser-Bessel digital filter for indepth investigation of events which had strong oscillations at periods close to the $6 \mathrm{~h}$ period.

The high-frequency series were further analysed, and the nine strongest events were extracted. Table 2 displays basic characteristics of each event, including the list of stations where the 9 strongest events were detected. All of the analysed events were recorded at three tide gauges at least and had maximum wave heights of at least $40 \mathrm{~cm}$. The duration of an event is defined as a time in which a wave height exceeds the threshold of $10 \mathrm{~cm}$, following a similar criterion introduced by Rabinovich and Monserrat (1996).

Spectral analysis was applied to sea level data, using a 2048 point length Kaiser-Bessel window (Emery and Thomson, 2001), $75 \%$ overlapped, over a five-day period (7200 point), centred over the maximum observed oscillations. Additional smoothing over high frequencies was performed by window averaging, which increases the degrees of freedom. Cross-spectra and coherence spectra were computed between pairs of stations, in order to document the standing or propagating nature of the observed oscillations, using the same procedure as for spectral analysis.

Following Marcos et al. (2009), we computed separately event and background spectra, the event spectra centred over the event, and the background spectra over calm intervals. Event-to-background spectral ratios were estimated in order to separate local topographic effects from energy of the observed ocean waves.

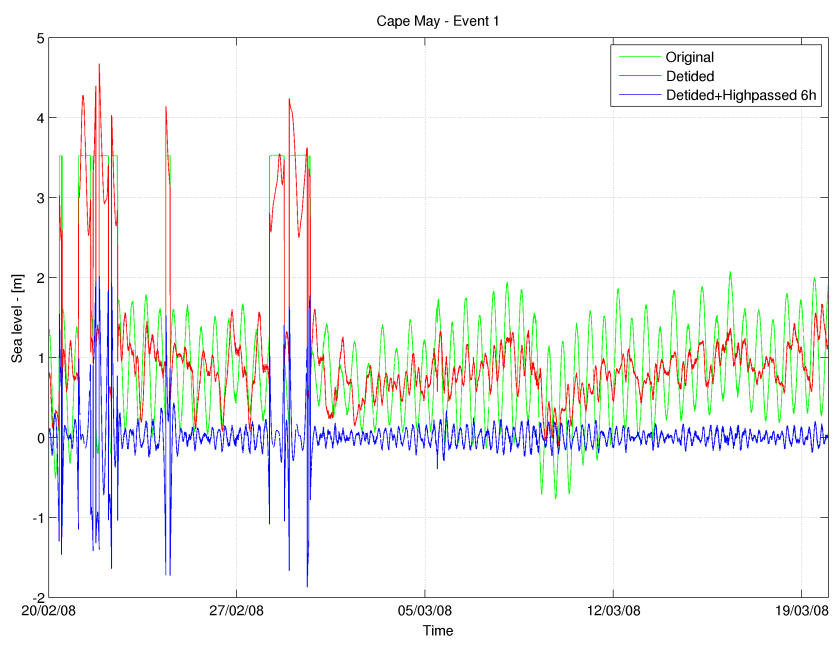

Fig. 2. Temporal evolution of 1-min raw sea level data containing bad data at the Cape May station between 20 February and 20 March 2008. Raw data (green), detided data (red) and high-pass filtered data (blue) are represented.

\section{Results}

Time series containing the strongest oscillations from three representative stations during all nine events are presented in Fig. 3. At first sight, we can observe a wide variety of oscillations, differing in oscillating periods, amplitudes and duration. Also, it is interesting to notice that most of the oscillations occurred from January to early April, except events 2 (June) and 9 (late October).

Maximum recorded oscillations were found to have wave heights between 40 and $100 \mathrm{~cm}$. The highest oscillations were recorded during events 6 and 7 at the Boston and Atlantic City tide gauges, respectively. Dominant periods were found to range from less than $1 \mathrm{~h}$ to $5-6 \mathrm{~h}$ periods. The events with longer periods lasted longer, on average about $20 \mathrm{~h}$, while some events were characterized by an isolated abrupt sea level peak over tens of minutes' timescale (e.g. the event no. 4 at Duck).

A variety of differences between the investigated events indicates a difference in the underlying physics. The most common property was a slow increase of wave amplitude during several hours. During the same event, waves were usually out of phase at different stations (e.g. at Sandy Hook, Atlantic City, Cape May during events 1, 3 and 7). On the other hand, the major wave peak observed during event 6 exhibits an in-phase behaviour between stations. Differently, event 8 shows again another kind of configuration, where one can observe the superposition of strong high-frequency oscillations at Trident Pier, presumably amplified within a harbour or bay, over lower frequency oscillations, the latter slowly decaying in time. 
Table 2. List of strong sea level oscillation events, their dominant period, maximum wave height and duration, and tide gauges where the oscillations have been recorded.

\begin{tabular}{|c|c|c|c|c|c|}
\hline Events & Date & $\begin{array}{r}\text { Dominant } \\
\text { period }\end{array}$ & Duration & $\begin{array}{l}\text { Maximum } \\
\text { wave height }\end{array}$ & $\begin{array}{l}\text { Stations where the } \\
\text { waves were recorded }\end{array}$ \\
\hline 1 & 05/03/2008 & $5-6 \mathrm{~h}$ & $24 \mathrm{~h}$ & $0.5 \mathrm{~m}$ (Atlantic City) & Montauk, Sandy Hook, Atlantic City \\
\hline 2 & $17 / 06 / 2008$ & $60 \mathrm{~min}$ & $20 \mathrm{~h}$ & $0.4 \mathrm{~m}$ (Duck) & $\begin{array}{l}\text { Montauk, Sandy Hook, Atlantic City, Ocean } \\
\text { City, Chesapeake, Duck }\end{array}$ \\
\hline 3 & 08/01/2009 & $3-4 h$ & $24 \mathrm{~h}$ & 0.5 m (Atlantic City) & $\begin{array}{l}\text { Bar Harbor, Boston, Montauk, Atlantic City, } \\
\text { Chesapeake, Duck, Beaufort, Wrightsville } \\
\text { Beach, Springmaid }\end{array}$ \\
\hline 4 & 29/01/2009 & $1 \mathrm{~h}$ & $1 \mathrm{~h}$ & $0.6 \mathrm{~m}$ (Duck) & Atlantic City, Ocean City, Duck \\
\hline 5 & $29 / 03 / 2009$ & $5-6 h$ & $24 \mathrm{~h}$ & $0.5 \mathrm{~m}$ (Wrightsville Beach) & $\begin{array}{l}\text { Duck, Beaufort, Wrightsville Beach, Spring- } \\
\text { maid Pier }\end{array}$ \\
\hline 6 & $26 / 02 / 2010$ & $3 \mathrm{~h}$ & $17 \mathrm{~h}$ & $1 \mathrm{~m}$ (Boston) & Bar Harbor, Portland, Boston \\
\hline 7 & $13 / 03 / 2010$ & $60 \mathrm{~min}$ & $48 \mathrm{~h}$ & $1 \mathrm{~m}$ (Atlantic City) & $\begin{array}{l}\text { Montauk, Sandy Hook, Atlantic City, Ocean } \\
\text { City, Chesapeake, Duck, Beaufort, Wrightsville } \\
\text { Beach }\end{array}$ \\
\hline 8 & 05/04/2011 & $60 \mathrm{~min}$ & $16 \mathrm{~h}$ & 0.7 m (Trident Pier) & $\begin{array}{l}\text { Atlantic City, Ocean City, Chesapeake, Duck, } \\
\text { Beaufort, Wrightsville Beach, Springmaid Pier, } \\
\text { Fort Pulaski, Trident Pier }\end{array}$ \\
\hline 9 & $28 / 10 / 2011$ & $40 \mathrm{~min}$ & $6 \mathrm{~h}$ & $0.5 \mathrm{~m}$ (Duck) & Atlantic City, Ocean City, Chesapeake, Duck \\
\hline
\end{tabular}

\subsection{Event of 5 March 2008}

Sea level oscillations became apparent during the morning and midday hours of 5 March 2008, slowly decaying and disappearing a day later. The strongest sea level signal was found at Atlantic City and Sandy Hook, where trough-tocrest values reached 85 and $45 \mathrm{~cm}$, respectively (Fig. 4). Three strong waves were observed at each station, followed by slowly decaying oscillations. Recorded oscillations had roughly $5 \mathrm{~h}$ periods with some higher frequency waves superimposed, particularly at Atlantic City where a $60 \mathrm{~cm}$ negative peak was recorded at the beginning of the event. The $5 \mathrm{~h}$ oscillations are not in phase. Namely, sea level begins to increase at 06:00 UT at Atlantic City, whereas at Sandy Hook, Lewes, Ocean City and Montauk the increase begins at 06:00 a.m., 09:00 a.m., 08:00 a.m. and 11:00 a.m., respectively. Also, the Atlantic City and Sandy Hook records are clearly out of phase. This phase shift could be a sign of waves propagating along the coastline.

The propagation velocity can be determined by taking peak-to-peak time differences between the stations. In order to better visualize peaks of interest, times series were bandpass filtered to keep periods between $2 \mathrm{~h}$ and $6 \mathrm{~h}$ (not shown). The relationship between time difference of sea level peaks versus alongshore distance can be seen in Fig. 5. Quasi-linear relationship between Sandy Hook and Lewes becomes visible, equivalent to a phase speed of $18.0 \mathrm{~m} \mathrm{~s}^{-1}$, and between Sandy Hook and Cape May to a phase speed of $16.3 \mathrm{~m} \mathrm{~s}^{-1}$. The propagation of the waves along the coastline is southward.

Spectral analysis (Fig. 6) shows that high-frequency sea level oscillations contained the most energy at Atlantic City.
Smaller energy differences were found at periods of 5 to $6 \mathrm{~h}$, with a maximum of energy at Sandy Hook and Atlantic City. Event-to-background spectral ratios exhibit a common behaviour: a broad maximum may be found between 3.5 and $6 \mathrm{~h}$, with a pronounced peak at $5.5 \mathrm{~h}$, and another broad maximum between 1.6 and $2.7 \mathrm{~h}$. At higher frequencies spectral ratios do not contain maxima; the only exception being Sandy Hook, where a broad event-to-background energy maximum may be found between 45 and $60 \mathrm{~min}$. Crossspectral analysis confirms that these two parts of the spectrum $(3.5-6 \mathrm{~h}$ and $1.6-2.7 \mathrm{~h})$ are coherent over the stations, with high coherence levels varying between 0.7 and 0.9 . The phase shift between pairs of stations is estimated, resulting in a phase difference of $90-100^{\circ}$ between Atlantic City and Cape May, $100^{\circ}$ between Atlantic City and Lewes and $-120^{\circ}$ between Atlantic City and Sandy Hook. The phase differences between Atlantic City and Sandy Hook and between Atlantic City and Cape May are roughly in agreement with estimates based on visual inspection of the series (Fig. 5).

Velocities computed from the cross-spectral phase differences, the respective periods, and alongshore distance between a pair of stations are reported in Table 3 . We can note the similarities between velocities estimated by both methods, indicating a dominance of the most pronounced oscillations around $5-6 \mathrm{~h}$. Phase information as well as visual inspection of sea level time series confirm that the recorded waves propagated southwards along the coast.

Synoptic analysis of the meteorological conditions revealed the presence of a low pressure system $(\sim 995 \mathrm{hPa})$ with a centre positioned inland (100-300 km from the shore) that travelled fast to the northeast with an average speed of $22 \mathrm{~m} \mathrm{~s}^{-1}$. The associated cold front passed over the 


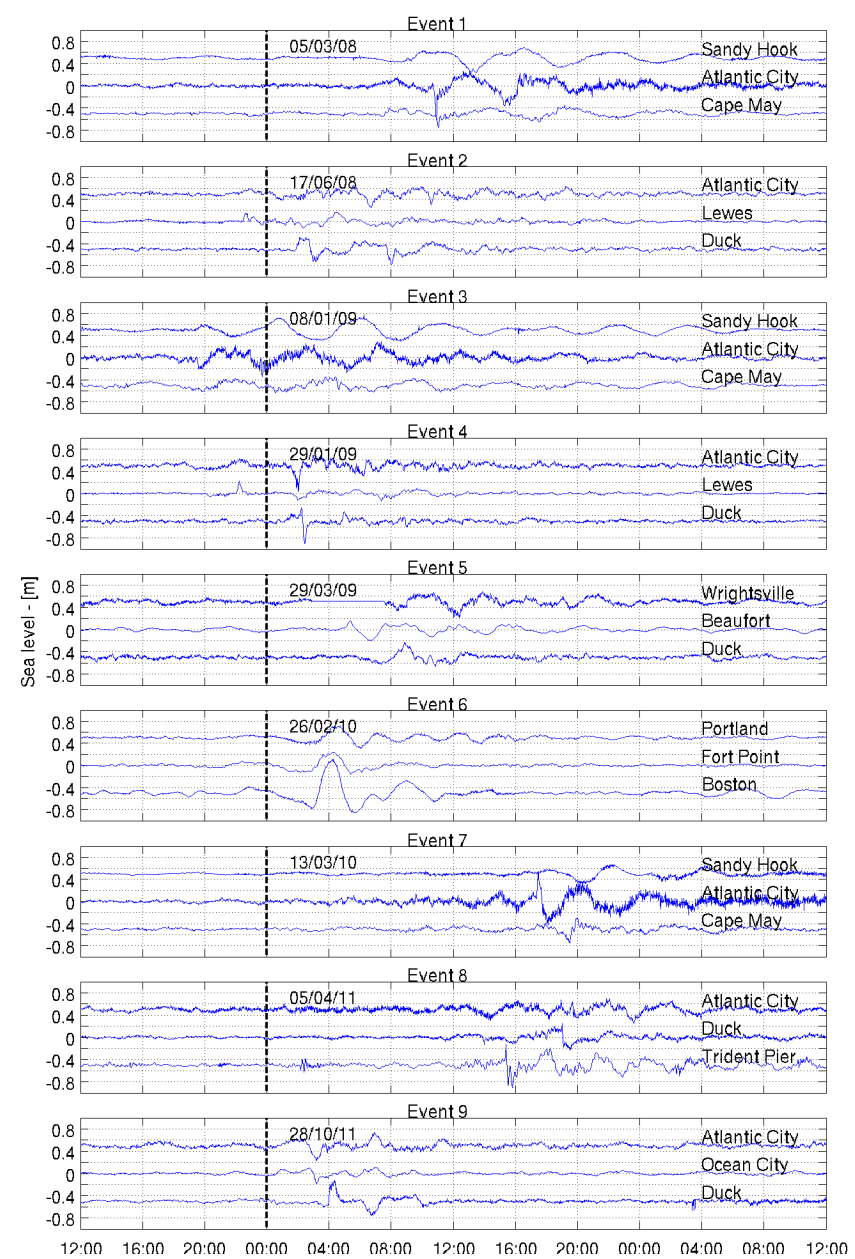

Fig. 3. Time series of residual sea level oscillations (in meters) from three stations with most intense oscillations for each of the listed 9 events. Residuals were high-pass filtered with $6 \mathrm{~h}$ Kaiser-Bessel digital filter. Vertical dashed lines stand for 00:00 UTC of the date indicated.

investigated area in late morning and midday hours, resulting in an abrupt pressure changes. Matching between the passage of the cold front and the occurrence of sea level oscillations is apparent.

A feasible explanation for the observed waves, ranging over super-inertial periods and propagating over a shelf area, is that they may be edge waves presumably generated by an impulse from the atmosphere (Huthnance, 1975), as similar oscillations $(6 \mathrm{~h})$ generated by a hurricane were found propagating along the Florida Coast (Yankovsky, 2008, 2009). To support the hypothesis, an analytical model for propagation of edge waves (see details in Appendix A) will be applied to our area and compared to observations. Considering a constant slope $\alpha=0.0006 \mathrm{rad}$, valid for the considered region, and peak periods of $4.8 \mathrm{~h}$ and $5.6 \mathrm{~h}$ characterized by highest spatial coherence, one can estimate edge wave velocity for the lowest wave mode. These values are reported in Table 3.

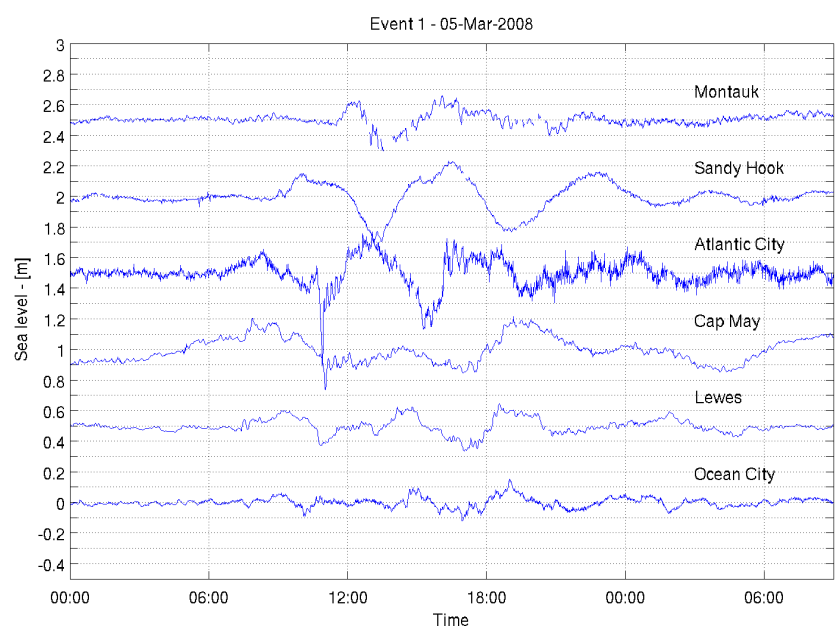

Fig. 4. Sea level time series during event 1. Series have been vertically offset for better presentation. Residuals were high-pass filtered with $12 \mathrm{~h}$ Kaiser-Bessel digital filter.

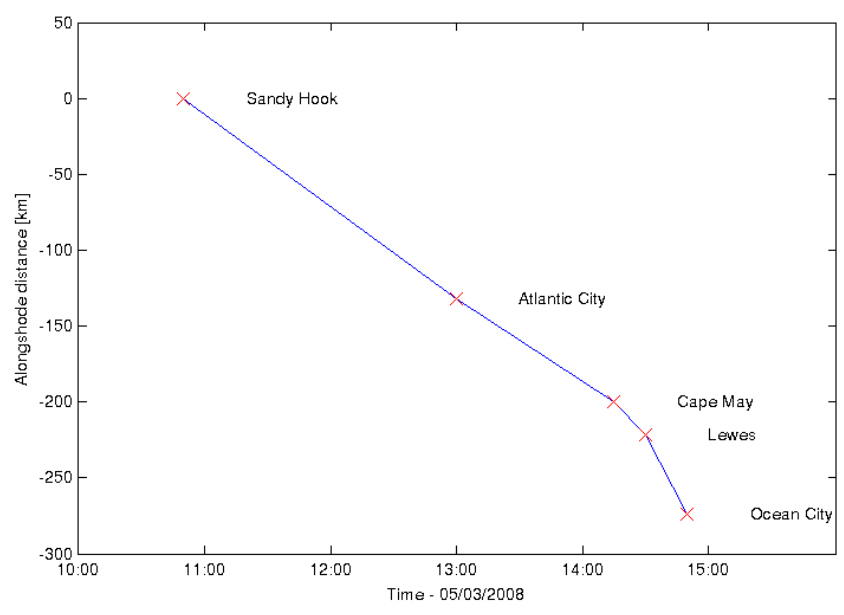

Fig. 5. Position in the time and alongshore distance of wave crests for each station during event 1 .

For the lowest mode ( $n=0$, also called Stokes mode), which is normally found to be the most intense one along the Florida shelf (Yankovsky, 2008), theoretical velocity varies from 16.2 to $18.9 \mathrm{~m} \mathrm{~s}^{-1}$, depending of the frequency considered. Considering the approximations, uncertainties and alongshore changes of $\alpha$, a fair matching with the observed velocity of 16.3 to $18.0 \mathrm{~m} \mathrm{~s}^{-1}$ is reached. Other modes were not significant during the event, allowing no proper detection of their phase difference and contemporary velocity estimates from the sea level data.

\subsection{Event of 13 March 2010}

Event no. 7 (Table 2) occurred on 13 March 2010. This event occurred in the same region and was detected at the 
Table 3. Periods and velocities inferred for events 1 and 7 using visual inspection, phase-shift and with analytical model, at Sandy Hook, Atlantic City and Cape May.

\begin{tabular}{|c|c|c|c|c|c|c|c|}
\hline \multirow{3}{*}{$\begin{array}{l}\text { Stations } \\
\text { Period (h) }\end{array}$} & \multicolumn{2}{|c|}{ Event 1} & \multicolumn{5}{|c|}{ Event 7} \\
\hline & \multicolumn{2}{|c|}{ Atlantic City/Cape May } & \multicolumn{5}{|c|}{ Sandy Hook/Atlantic City } \\
\hline & 5.6 & 4.8 & 5.6 & 4.8 & 2.8 & 2.6 & 1.3 \\
\hline Velocity (from visual inspection) $\left(\mathrm{m} \mathrm{s}^{-1}\right)$ & \multicolumn{2}{|c|}{16.3} & \multicolumn{5}{|c|}{16.3} \\
\hline Velocity (using phase information) $\left(\mathrm{m} \mathrm{s}^{-1}\right)$ & 16.3 & 19.2 & 11.8 & 14.2 & 8.1 & 8.3 & 4.3 \\
\hline $\begin{array}{l}\text { Velocity (from analytical model, Stokes mode } \\
n=0)\left(\mathrm{m} \mathrm{s}^{-1}\right)\end{array}$ & 18.9 & 16.2 & 18.9 & 16.2 & 9.6 & 8.9 & 4.4 \\
\hline
\end{tabular}
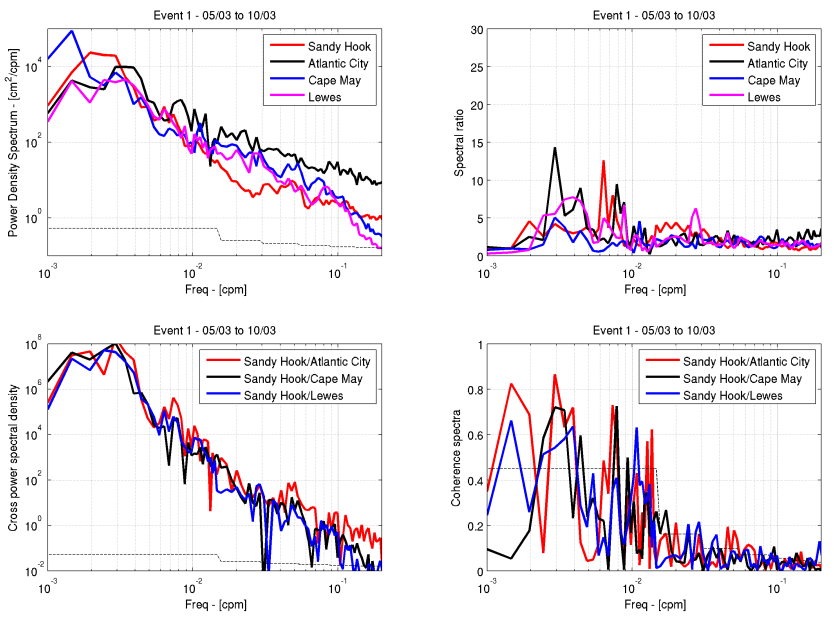

Fig. 6. Power spectra, power spectral ratios, cross spectra and coherence spectra of the $12 \mathrm{~h}$ high-pass filtered residual sea level series during event 1 . Ninety-five percent (95\%) confidence level is indicated by dashed lines.

same stations as during event 1 (Fig. 7). The biggest crestto-trough values were again recorded at Atlantic City and reached $95 \mathrm{~cm}$, and at Cape May, where they reached $40 \mathrm{~cm}$. The oscillations between stations seem to be phase shifted, as for event 1. For instance, the oscillations recorded at Atlantic City and Sandy Hook are clearly out of phase. The observed oscillations predominantly consist of low frequency oscillations (4-5 h), on which higher frequency waves are superimposed; the latter again with higher amplitudes at Atlantic City as during event 1.

Between Sandy Hook and Nantucket the phase velocity is estimated at $29.6 \mathrm{~m} \mathrm{~s}^{-1}$ from the $2-6 \mathrm{~h}$ filtered series and their peak occurrences at different stations (Fig. 8), while between Atlantic City and Sandy Hook it equals $16.3 \mathrm{~m} \mathrm{~s}^{-1}$. The latter velocity is similar to the one observed during event 1 . However, the wave velocity increased north of Sandy Hook, probably due to the narrowing of the shelf and an increase of the shelf slope $\alpha$. Also, estimated velocity is unrealistically higher than expected between Atlantic City and Cape May $\left(37.7 \mathrm{~m} \mathrm{~s}^{-1}\right)$, indicating a source area for the

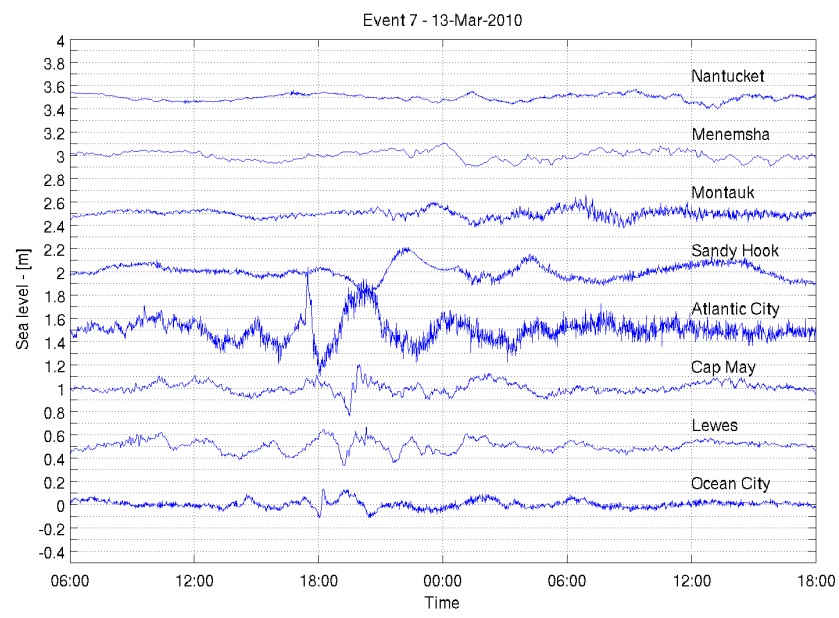

Fig. 7. Residual sea level time series recorded during event 7. Series have been vertically offset for better presentation. Residuals were high-pass filtered with a $12 \mathrm{~h}$ Kaiser-Bessel digital filter.

observed edge waves lying somewhere between these two stations, from which the waves were transmitted northward and southward along the coastline. Therefore, this velocity is unrealistic and should not be taken into consideration.

As for event 1, we performed spectral and cross-spectral analysis (Fig. 9). A similarity of spectra and spectral ratio between Lewes and Cape May may be found, both having strong significant peaks at 1.3 and $2.6 \mathrm{~h}$. Again, a broad energy maximum is found at low frequencies at Sandy Hook and Atlantic City. Atlantic City has dominant peaks at 4.8 and $2.4 \mathrm{~h}$, but its spectral ratio, however, has dominant peaks at $3.8,2.8$ and $0.9 \mathrm{~h}$.

The velocities have been computed using phase shift information derived from cross-spectral analysis for the periods with significant energies. We chose the following periods: 4.8, 2.8, 2.6 and $1.3 \mathrm{~h}$. However, the computed phase shift does not have the information about the number of waves lying between two neighbouring stations (each wave lying between stations adds $360^{\circ}$ to the phase difference), which is particularly relevant for oscillations at lower periods, and pure estimation of phase shift may result in unrealistic 


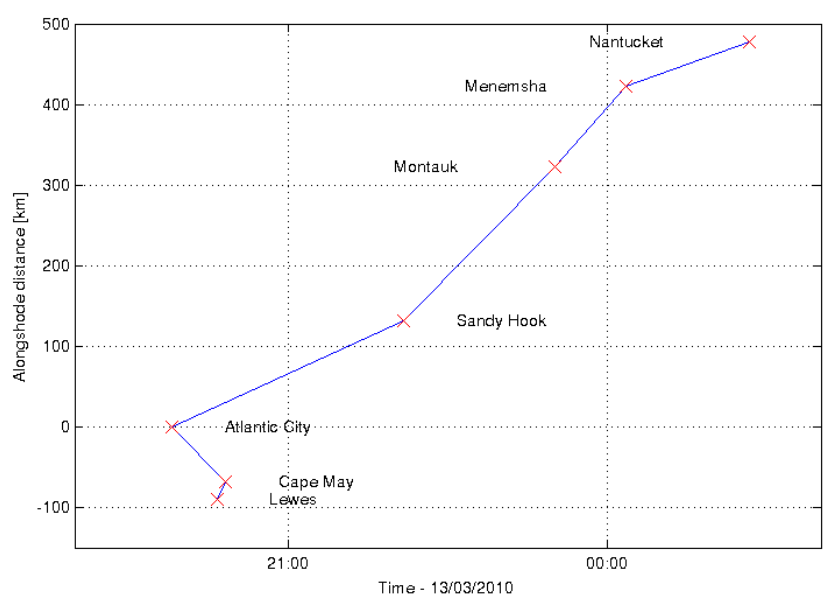

Fig. 8. Position in the time and alongshore distance of wave crests for each station during event 7.

overestimation of wave velocities. Therefore, we applied a number of narrow band-pass filters to series (not shown) to extract single-period oscillations, and to detect the number of waves lying between stations. For example, the time shift between Sandy Hook and Atlantic City maximum waves having periods between 2 and $3 \mathrm{~h}$ indicate that approximately 1.5 waves can be placed between these stations. Therefore, $360^{\circ}$ should be added on phase difference estimated from cross-spectra for waves at 2.6 and $2.8 \mathrm{~h}$ periods.

Finally, velocities estimated from the phase shift spectra and band pass filtering are summarized in Table 3. Different Stokes modes $(n=0)$ match fairly observed velocities for 1.3 and $2.6 \mathrm{~h}$ periods, and overestimate slightly the observed velocities documented at higher periods. Therefore, we can hypothesize that the observed waves were indeed edge waves, having source region south from Atlantic City and propagating northward as the lowest Stokes mode.

Different to event 1 , synoptic conditions during the event reveal the presence of a broad stationary cyclone, slowly moving eastward, accompanied with a cold front stretching offshore, passing over the investigated area in evening hours of 13 March 2010. Minimum air pressure has been recorded at Lewes and Sandy Hook around 06:00 p.m. Strong winds (above $10 \mathrm{~m} \mathrm{~s}^{-1}$ ) blew onshore (towards $\mathrm{W}$ ) at the front of the cyclone and offshore (towards SE) in its rear sector. Such a stationary situation might be favourable for wind-driven generation of edge waves travelling away from a stationary front as suspected from observations, but more detailed analysis of atmosphere-ocean coupling, including numerical modelling, should be undertaken to confirm the hypothesis and quantify the processes.

\subsection{Event of 26 February 2010}

Event 6 occurred during 26 February 2010 and was detected at the following stations: Bar Harbor, Portland, Wells, Fort
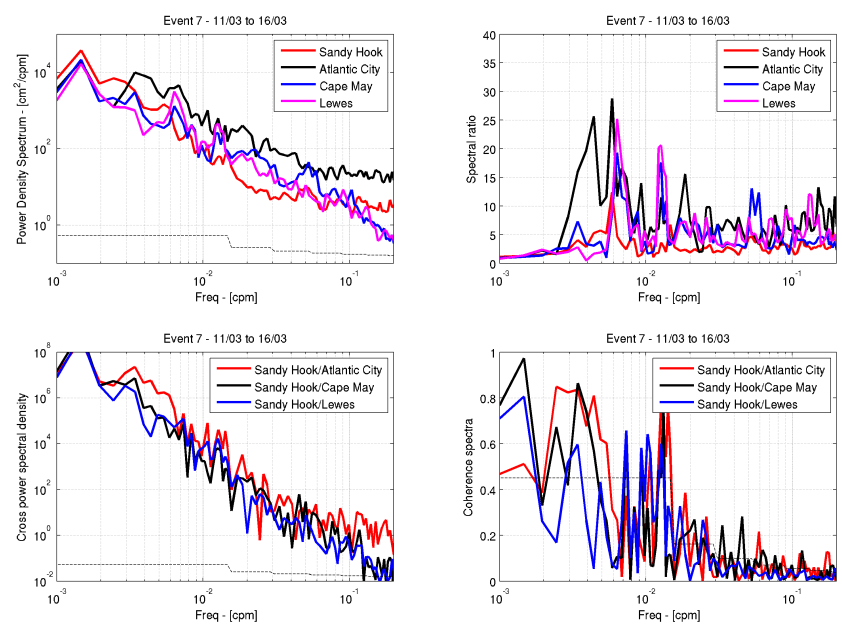

Fig. 9. Power spectra, power spectral ratios, cross spectra and coherence spectra, of the $12 \mathrm{~h}$ high-pass filtered residual sea level series during event 7 . Ninety-five percent $(95 \%)$ confidence level is represented by dashed lines.

Point and Boston (Fig. 1). Maximum trough-to-crest height of the wave reached $95 \mathrm{~cm}$ in Boston, $40 \mathrm{~cm}$ in Portland and $38 \mathrm{~cm}$ in Fort Point.

The pattern seems to be similar for all stations (Fig. 10). A slight increase of the sea level occurred during the last hours on 25 February, and sea level decreased significantly a few hours later. Then the highest wave appeared, followed by several decaying oscillations. The number of oscillations depends of the station: there were several of them in Portland $(>10)$ and just one in Fort Point. The highest wave amplitude occurred at the same time at all stations, between 04:00 and 05:00 a.m. on 26 February.

Spectral analysis (Fig. 11) documents the highest eventto-background spectral ratios in Boston, Portland and Fort Point. There is a high degree of similarity between spectral ratios at Fort Point and Boston, both having sharp peaks at $4.8-5.6 \mathrm{~h}$ and $2.6-2.8 \mathrm{~h}$. Spectral ratio in Wells has a similar shape but is weaker, probably due to position of the tide gauge inside a lagoon. At Portland, two peaks may be found at 2.0 and $2.6 \mathrm{~h}$, and a broader one over periods greater than $4 \mathrm{~h}$. At the northernmost station, Bar Harbor, there are no strong spectral peaks at specific frequencies, indicating that the event did not occur significantly there. It is worth noting also that for all stations but Boston, the slope of the spectral ratio increases with the frequency, indicating a strong effect of the forcing at short timescales.

Cross spectral analysis (Fig. 11) indicates that oscillations posed a high level of coherence between Boston, Fort Point and Portland. Boston and Fort Point oscillations were roughly in phase at 2.6/2.8 and $4.8 \mathrm{~h}$ (Table 4 ), and had a high level of coherence. The coherence at $4.8 \mathrm{~h}$ period was high also between Portland and Boston/Fort Point, with a slight phase shift $(20 \mathrm{deg})$. Therefore, it seems that the 


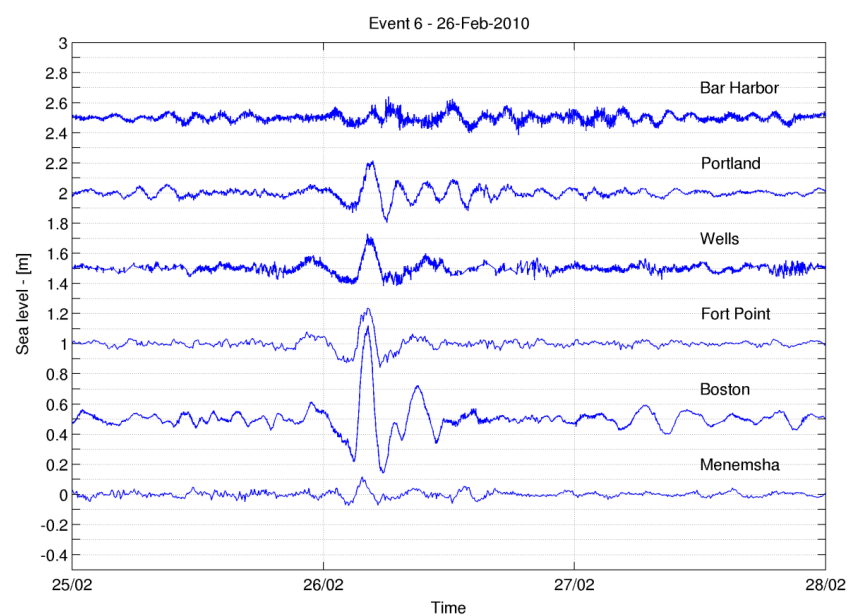

Fig. 10. Residual sea level time series during the event 6. Series have been vertically offset for better presentation. Residuals were high-pass filtered with a $6 \mathrm{~h}$ Kaiser-Bessel digital filter.
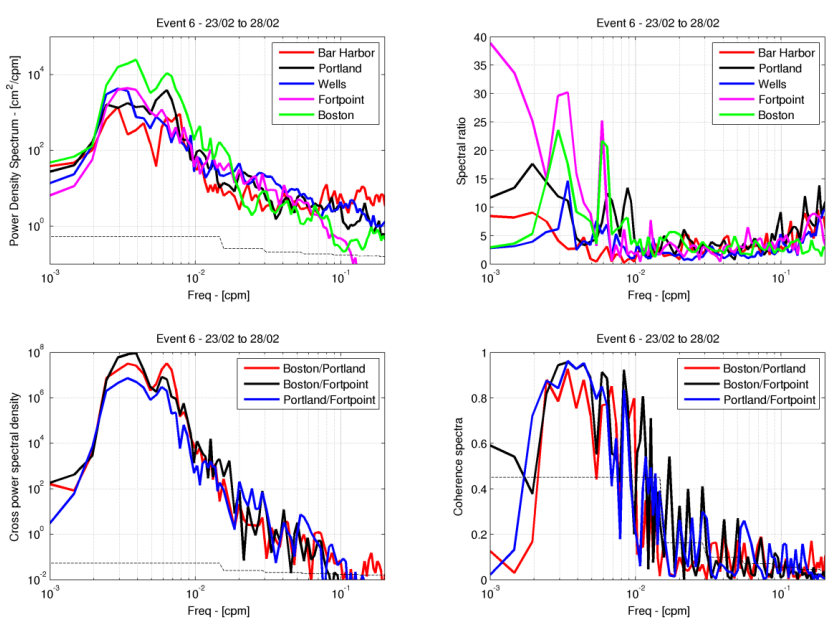

Fig. 11. Power spectra, power spectral ratios, cross spectra and coherence spectra, of the $6 \mathrm{~h}$ high-pass filtered residual sea level series during event 7 . Ninety-five percent $(95 \%)$ confidence level is represented by dashed lines.

$4.8 \mathrm{~h}$ oscillations may be attributed to a fundamental mode of standing waves generated over the shelf, encompassing the region from Cape Cod Bay to north of Portland, while 2.6/2.8 $\mathrm{h}$ oscillation probably corresponded to the first mode. Finally, the $2 \mathrm{~h}$ oscillations observed at Portland and not observed at Fort Point and Boston were possibly related to some standing oscillations occurring in a complex Portland area bathymetry. The observed stationary nature of these sea level oscillations and their spatial outreach should be confirmed through numerical modelling.

Synoptic analysis reveals a deep eye-like low pressure system travelling northward toward the Massachusetts shelf during afternoon and evening hours of 25 February. Around
Table 4. Significant coherences and phase shifts during event 6 for several periods between Portland, Fort Point, and Boston tide gauge stations.

\begin{tabular}{lrrrrr}
\hline \multirow{2}{*}{ Coherence } & \multicolumn{5}{c}{ Period } \\
\cline { 2 - 6 } & $2 \mathrm{~h}$ & $2.4 \mathrm{~h}$ & $2.6 \mathrm{~h}$ & $2.8 \mathrm{~h}$ & $4.8 \mathrm{~h}$ \\
\hline Boston/Portland & & 0.85 & 0.77 & & 0.93 \\
Boston/Fort Point & 0.92 & & 0.88 & 0.91 & 0.95 \\
Portland/Fort Point & 0.83 & & & 0.85 & 0.96 \\
Phase-Shift $\left({ }^{\circ}\right)$ & & & & & \\
Boston/Portland & & 83 & 62 & & 18 \\
Boston/Fort Point & -24 & & -6 & -5 & -4 \\
Portland/Fort Point & -118 & & & -25 & -23 \\
\hline
\end{tabular}

midnight the cyclone reached the minimum central pressure of $972 \mathrm{hPa}$ and were positioned about $100 \mathrm{~km}$ south of Massachusetts coastline, then turned sharply westward. An associated cold front passed over the Massachusetts and Maine shelf during the morning hours of 26 February. As the Massachusetts and Maine coastal area was positioned northeastward from the cyclone centre, the winds blew strongly onshore, e.g. average wind speed measured at station Wells in the late evening hours of 25 February reached $20 \mathrm{~m} \mathrm{~s}^{-1}$ and blew from $\mathrm{E}$ to NE. The winds relaxed after the frontal passage, enabling oscillatory sea level movements in the area.

\section{Discussion and conclusions}

The objective of this paper was to document and examine the most interesting high-frequency $(<6 \mathrm{~h})$ sea level events extracted from 20 tide gauges operating along the US East Coast between 2006 and 2011. Nine intense events, with a maximum recorded wave height from 40 to $100 \mathrm{~cm}$, have been selected for analysis.

A number of past studies investigated similar highfrequency sea level events along the US. East Coast (Churchill et al., 1995; Paxton and Sobien, 1998; Yankovsky, 2008). However, these studies were based on local and sparse measurements of lower quality. This study systematically investigates 1-min raw sea level data over a longer time interval and over a larger area, directly benefiting from the upgrade of sea level network following the 2004 Sumatra devastating tsunami. As the tsunami network with a 1-min resolution may be found on the US West Coast as well, and high-frequency phenomena has been recorded there also (Thomson et al., 2009), it would be interesting to compare high-frequency sea level oscillations observed at the US East Coast with oscillations observed at the US West Coast. Meteorological conditions and topographical features are different along the two coasts. As for the latter, the US East Coast is characterized by a wide shelf, while the US West Coast is characterized by a narrow shelf, allowing an assessment 
of the importance and efficiency of wide shelves in trapping and amplifying high-frequency energy from the atmosphere.

The importance of a proper data quality control should be emphasized, as a number of bad quality data have been detected in the raw 1-min sea level measurements. Presently, 6-min sea level data are quality controlled by the National Oceanic and Atmospheric Administration, but such a resolution is not sufficient to properly investigate some high-frequency sea level phenomena, such as meteotsunamis (Monserrat et al., 2006). Therefore, the need for 1-min sea level quality-checked data for research purposes is a demand.

We documented a variety of processes, which should be analysed in-depth and connected to their source in the atmosphere. A preliminary synoptic analysis of events 1, 6 and 7 point to the extra-tropical cyclones and associated frontal zones as the source for the observed sea level oscillations; however, atmospheric sources may include (i) hurricanes and tropical cyclones, which can have direct and indirect impact; direct impact comes from landfall effects (Yankovsky, 2008, 2009), but indirect impact is a result of hurricane and tropical cyclone passages over variable bathymetry and shelf areas (Mercer et al., 2002; Mecking et al., 2009); (ii) extratropical cyclones which can quasi-resonantly excite long ocean waves propagating along a wide shelf (Munk et al., 1956; Beardsley et al., 1977); and (iii) high-frequency propagating atmospheric disturbances and gravity waves, which can resonantly generate long ocean waves over minutes to an hour timescale though Proudman or Greenspan resonances (Proudman, 1929; Greenspan, 1956). All of these processes may result in strong high-frequency sea level oscillations, and their relevance should be investigated further by numerical modelling tools.

Particularly strong oscillations have been observed in a shallow region delimited by Boston and Portland. As an explanation, we may assume that these oscillations are a result from combination of different resonance mechanisms, openocean Proudman resonance and harbour resonance. The first may occur over the 20-60 m-deep shallow area bordered to the south by Cape Cod, corresponding to long ocean wave speed of $15-25 \mathrm{~m} \mathrm{~s}^{-1}$. The second is determined by the coastline shape, as the highest waves were observed in Boston, which is placed in a cone-shaped bay which, especially at its top, allows for the strong oscillation amplification (Rabinovich, 2009). This hypothesis should be checked through a numerical modelling approach applied to a highresolution bathymetry.

Our study documents an extraction and basic-level research of the strongest events that occurred over a wide region; however, another approach is feasible and includes thorough investigations and statistics of high-frequency oscillations collected at a "beacon" station - the station which might be particularly sensible to high-frequency oscillations over minutes to hours timescales. This may be particularly interesting to the local authorities, as some of these oscillations are observed in large harbours, prone to heavy ship and cargo traffic (Wang et al., 1987; de Jong and Battjes, 2004; Vilibić and Mihanović, 2005). For instance, Wang et al. (1987) studied 23-yr-long sea level time series in the Bohai Bay (China) and documented statistics of all identified strong seiche events, enabling an estimation of seiche return periods. Applying this procedure to all stations along the US coastline (and not only there) would allow a delimitation of "high risk" areas. For instance, Atlantic City is found to be largely sensible to high-frequency oscillations, which may be quite important in harbours with large amplification factors (Rabinovich, 2009). Combining both process-oriented and hotspot-oriented research of high-frequency phenomena is necessary to obtain proper information for hazard and risk assessment studies.

\section{Appendix A}

A simple analytical model for propagation of edge waves developed by Ursell (1952) and used by Yankovsky (2008) has been used in this analysis. The analytical theory was developed for edge waves propagating along a shelf of a constant slope, and can be applied to the US East Coast shelf.

The model considers three-dimensional normal modes propagating over a shelf with constant slope $\alpha$. The dispersion relation is given by (Yankovsky, 2008)

$\sigma^{2}=g k \sin ((2 n+1) \alpha)$,

where $\sigma$ is the wave frequency, $g$ is the acceleration due to gravity, $k$ is the wave number and $n$ is the mode number. The slope parameter $\alpha$ equals to $0.0006 \mathrm{rad}$, and is computed from the distance between coastline and $50 \mathrm{~m}$ isobath in the area of Atlantic City, where the strongest edge waves were detected. Considering that $c=\frac{g}{\sigma}$, one can compute theoretical velocity $c$ of different edge wave modes

$c=\frac{g}{\sigma}((2 n+1) \alpha)$.

Acknowledgements. We greatly appreciate comments provided by two anonymous reviewers. This work was conducted within the NOAA/NWS project "Towards a meteotsunami warning system along the US coastline (TMEWS)", Award no. NA11NWS4670005.

Edited by: S. Tinti

Reviewed by: A. E. Yankovsky and one anonymous referee 


\section{References}

Beardsley, R. C., Mofjeld, H., Wimbush, M., Flagg, C. N., and Vermersch Jr., J. A.: Ocean tides and weather induced bottom pressure fluctuations in the Middle-Atlantic Bight, J. Geophys. Res., 82, 3175-3182, 1977.

Bernard, E. N., Mofjeld, H. O., Titov, V., Synolakis, C. E., and Gonzalez, F. I.: Tsunami: scientific frontiers, mitigation, forecasting and policy implications, Phil. T. R. Soc. A, 364, 1989-2007, doi:10.1098/rsta.2006.1809, 2006.

Churchill, D. D., Houston, S. H., and Bond, N. A.: The Daytona Beach Wave of 3-4 July 1992: A Shallow-Water Gravity Wave Forced by a Propagating Squall Line, Bull. Am. Meteorol. Soc., 32, 21-32, 1995.

De Jong, M. P. C. and Battjes, J. A: Low-frequency sea waves generated by atmospheric convection cells, J. Geophys. Res., 109, C01011, doi:10.1029/2003JC001931, 2004.

Donn, W. L. and Balachandran, N. K.: Coupling between a moving air-pressure disturbance and the sea surface, Tellus, 21, 701-706, 1969.

Donn, W. L. and McGuinness, W. T.: Air-Coupled Long Waves in the Ocean, J. Atmos. Sci., 17, 515-521, 1960.

Eliot, M. and Pattiaratchi, C.: Remote forcing of water levels by tropical cyclones in southwest Australia, Cont. Shelf Res., 30, 1549-1561, 2010.

Emery, W. J. and Thomson, R. E.: Data analysis methods in physical oceanography, Elsevier Science, 2001.

Greenspan, H. P.: The generation of edge waves by moving pressure disturbances, J. Fluid Mech., 1, 574-592, 1956.

Huthnance, J. M.: On trapped waves over a continental shelf, J. Fluid Mech., 69, 689-704, 1975.

LeBlond, P. H. and Mysak, L. A.: Waves in the Ocean, Elsevier, Amsterdam, 602 pp., 1978.

Marcos, M., Monserrat, S., Medina, R., Orfila, A., and Olabarrieta, M.: External forcing of meteorological tsunamis at the coast of the Balearic Islands, Phys. Chem. Earth, 34, 938-947, 2009.

Mecking, J. V., Fogarty, C. T., Greatbatch, R. J., Sheng, J., and Mercer, D.: Using atmospheric model output to simulate the meteorological tsunami response to Tropical Storm Helene (2000), J. Geophys. Res., 114, C10005, doi:10.1029/2009JC005290, 2009.

Mercer, D., Sheng, J., Greatbatch, R. J., and Bobanović, J.: Barotropic waves generated by storms moving rapidly over shallow water, J. Geophys. Res., 107, 3152, doi:10.1029/2001JC001140, 2002.
Monserrat, S., Vilibić, I., and Rabinovich, A. B.: Meteotsunamis: atmospherically induced destructive ocean waves in the tsunami frequency band, Nat. Hazards Earth Syst. Sci., 6, 1035-1051, doi:10.5194/nhess-6-1035-2006, 2006.

Munk, W. H., Snodgrass, F., and Carrier, G.: Edge waves on the continental shelf, Science, 123, 127-132, 1956.

Pawlowicz, R., Beardsley, B. and Lentz, S.: Classical tidal harmonic analysis including error estimates in MATLAB using T_TIDE, Comput. Geosci., 28, 929-937, 2002.

Paxton, C. H. and Sobien, D. A.: Resonant interaction between an atmospheric gravity wave and shallow water wave along Florida's west coast, Bull. Am. Meteorol. Soc., 79, 2727-2732, 1998.

Proudman, J.: The effects on the sea of changes in atmospheric pressure, Mon. Not. R. Astron. Soc. Geophys. Suppl., 2, 197-209, 1929.

Rabinovich, A. B.: Seiches and harbour oscillations, in: Handbook of Coastal and Ocean Engineering, World Scientific Press, Singapore, 193-236, 2009.

Rabinovich, A. B. and Monserrat, S.: Meteorological tsunamis near the Balearic and Kuril Islands: Descriptive and statistical analysis, Nat. Hazards, 13, 55-90, 1996.

Sallenger Jr., A. H., List, J. H., Gelfenbaum, G., Stumpf, R. P., and Hansen, M.: Large wave at Daytona Beach, Florida, explained as a squall-line surge, J. Coast. Res., 11, 1383-1388, 1995.

Thomson, R. E., Rabinovich, A. B., Fine, I. V., Sinnott, D. C., McCarthy, A., Sutherland, N. A. S., and Neil, L. K.: Meteorological tsunamis on the coasts of British Columbia and Washington, Phys. Chem. Earth, 34, 971-988, 2009.

Ursell, F.: Edge waves on a sloping beach, Proc. Roy. Soc. London, 214, 79-97, 1952.

Vennell, R.: Resonance and trapping of topographic transient ocean waves generated by a moving atmospheric disturbance, J. Fluid. Mech., 650, 427-442, 2010.

Vilibić, I. and Mihanović, H.: Resonance in Ploče Harbor (Adriatic Sea), Acta Adriatica, 46, 125-136, 2005.

Yankovsky, A. E.: Long-Wave Response of the West Florida Shelf to the Landfall of Hurricane Wilma, October 2005, J. Coast. Res., 24, 33-39, 2008.

Yankovsky, A. E.: Large-scale edge waves generated by hurricane landfall, J. Geophys. Res., 114, C03014, doi:10.1029/2008JC005113, 2009.

Wang, X., Li, K., Yu, Z., and Wu, J.: Statistical characteristics of seiches in Longkou Harbour, J. Phys. Oceanogr., 17, 1063-1065, 1987. 